\title{
What is happiness: a cross-cultural research into present-day associations
}

\author{
Irina N. Kabanova ${ }^{1 *}$, Anna M. Gorokhova ${ }^{1}$, Elena G. Nozhevnikova ${ }^{1}$, and Ekaterina $V$. \\ Vaseneva $^{2}$ \\ ${ }^{1}$ The Linguistics University of Nizhny Novgorod, Department of English Philology, Nizhny \\ Novgorod, Russia \\ ${ }^{2}$ The Linguistics University of Nizhny Novgorod, Department of the French, Spanish and Italian \\ Languages, Nizhny Novgorod, Russia
}

\begin{abstract}
The article under consideration is aimed at cross-cultural quantified associative mapping of the universal concept "happiness" and shaping the hierarchy of its cornerstone axiological constituents as perceived by Russian, French and English linguosocieties within the framework of the global pandemic reality. "Happiness" has been subject to transdisciplinary investigation since ancient times due to its dynamic character and ambiguity. The concept of "happiness", although psychologically ingrained and biologically predetermined, can change significantly based on different outer and inner factors. It demonstrates an undeniable potential for multiple perceptions, various patterns of ethnicspecific and highly personalized verbalization, requiring unification and analysis of different sociocultural stimuli that trigger off this or that row of associations. The authors provide keen insight into the semantics of the concept and its static lexicographic axiological paradigm in the Russian, French and English languages. Three associative surveys were carried out through Google-forms to estimate the degree at which the "static projection" of "happiness" is relevant nowadays in pandemic-shaken societies as well as collect free associations, manually contrast the data and establish parallels and peculiarities within up-to-date Russian, French and English (American) visions of "happiness". The survey results testify to the fact that "health", "family", "peace" and "freedom" are universally recognized constituents of "happiness" while certain elements prove to be ethnic-specific and arise due to concrete social circumstances.
\end{abstract}

Keywords: happiness, concept, associative map, national identity.

\section{Introduction}

"Happiness" in all its variations has always been and will remain the focus of numerous scientific investigations. D. Myers and E. Diener [1] while presenting elements of an appraisal-based theory of happiness established that the perception of personal "happiness" and degree of it "differ strikingly" among nations, with examples given (among others) that about $10 \%$ people in Portugal openly admit to being "very happy", while the opposite is

* Corresponding author: kabanova@lunn.ru 
true for Americans and only 1/10 describe themselves as "not very happy". The logical questions that followed and were brought into light by A. Wierzbicka [2] were "Is it true that nations differ in happiness? Or do they differ, rather, in what they are prepared to report about the state of their happiness?" [2, p. 35].

With the data available from the latest research into cognitive neuroscience (in particular The LaBar lab project) it can be objectively stated that "happiness" is acknowledged by the human brain variously and "distinct patterns correspond to easily identifiable emotions like amusement, surprise, contentment, fear, and anger" [3]. As A. Wierzbicka states, "it is an illusion to think that the English words happy and happiness have exact semantic equivalents in other European languages" [2]. The linguistic items representing them while being some of the core words in the national lexicon simultaneously refer to the culturally specific concepts associated with very different embodiments of causes, manifestations and influences of "happiness". The aim of the current research presented in this article it to identify which of the "associations" with happiness is prevalent in the contemporary world as seen by the representatives of different linguosocieties.

\section{Data and methods}

The database for the analysis was built through the associative experiment, free and guided, with the choice of options in the guided part being based on the range of preceding widely acknowledged linguistic investigations. The comparative analysis of synonymic lines and cross-reference of dictionary and thesaurus entries for the key lexemes revealed certain similarities in the "constituents" of the "state of happiness", "harmony" and "health" in particular being identified as the causes (in some sources) or semantic equivalents (in others) of "happiness", which instigated interest in the clarification of the cross-cultural status of other components, namely: which can at present be considered universal and the ranking of others in different cultures. The association surveys were carried out through Google-forms with two possible grouping factors included (age and gender) and the results of the computer calculated statistics were then manually contrasted to establish parallels and key differences between Russian, French and English (American) visions of "happiness". The limited choice ranking part allowed to check which "culturally established components of happiness" are more relevant (with the possibility in the form to give the same rank to several options the percentages will not equal 100 in the later text), while the free associations part allowed to identify potential new elements in the cognitive map of "happiness" in the present day society.

\section{Russian perception}

The associative map of constituents shaping Russian ethnic-specific perception of "happiness" incorporates a number of basic concepts of material and non-material nature among which "physical well-being and health", "commonality" (family, friendship, other interpersonal relations), "youth", "mood", "freedom", "a state of soul", "balance", "stability", "luck", "creature comforts" are differentiated [4]. "Happiness" as defined by Russian etymological dictionary is majorly connected with 'chance', 'success', 'bliss' and 'felicity' as well as the notion of sharing or being part of something good and noble and accepting one's lot [5].

The paremiological projection of "happiness" is representative of its ambiguity and emphasizes correlation with the contrasting concepts of misfortune and hardship; brings to the fore the significance of common sense, on the one hand, and states that fools enjoy the 
utmost of good luck, on the other hand. It is typified as a relatively deceptive, illusory and inconstant category. "Happiness" is personified as a woman, mother and servant to a man. It has its own character and free will. Quite representative is specifically Russian fatalistic approach to happiness - it is not advisable to search for it as it comes and goes of its own accord [6].

The initial (open) part of the survey among Russian-speaking respondents enables segmenting the list of provided free associations into several axiological-semantic layers based on their quantitative recurrence. Family relations: family, offspring, parents, mother. It is worth mentioning in this respect that "boyfriends" and "girlfriends" fall into a separate group, which is usually ranked second or third, while the immediate circle tends to occupy number one position on the respondents' priority scale. 'Health', thus, mainly has to do with "parents' health", which is representative of a pandemic-related associative shift, because the older generation is more prone to unfavourable consequences. Commonality: association with other people, making friends, acquaintances, being on amicable terms with colleagues and fellow-students. Peace and serenity: harmony with one's inner and outer world, emotional tranquillity, remaining self-possessed under any circumstances. Success: achieving goals, self-expression, self-realization, getting an excellent mark, having a good job and climbing the career ladder, victory, gaining a degree. Positive emotions: good mood, laughter, joy, hug, smile. Travelling: this association and its axiological synonyms is presumably triggered off by the pandemic restrictions that have deprived people of the opportunity to travel abroad, thus even "going to the countryside" or "weekend outing" are labelled as "happiness" markers. Freedom. Beauty. Money and general well-being. "Creature comforts": food, sweets, having a cuppa without any hurry, delicious dinner. Rest and relaxation. Weather conditions and seasons: sun, sunlight, warmth, summer, summertime, holiday season.

The ranking scale study shows quantitative predominance of "harmony" (80\%), "a certain state of soul" (68\%) corresponding to the primary position of the concept "soul" in Russian national concept-sphere, "freedom" (58\%), "health" (56\%) and commonality (52\%). "Stability" is looked upon as a slightly less significant (49\%) element, supposedly predetermined by the state of the current pandemic bringing about considerable uncertainty. Such notions as "success", "mood", and "youth" enjoy less striking popularity with the utmost of 42 to $45 \%$. "Creature comforts", surprisingly, stand among the least frequently traced features, as only $30 \%$ of the respondents believe their happiness to be dependent on attaining them. The latter is rooted in typically Russian axiological paradigm based on nonmaterial, spiritual-emotive values.

The results of the undertaken survey correspond to the latest Russian Public Opinion Research Center (VTsIOM) poll, aimed at estimating the degree of Russians' happiness within the timeline of the COVID-19 pandemic. According to the research, the cornerstone constituents of "happiness" lie within the triad of "family" (29\%), "relatives' health" (25\%), and "having kids" (14\%) [7].

\section{French perception}

The core meaning of "happiness" for this part was derived primarily from the dictionaries Le Petit Robert and Larousse, according to which the main "constituent" of "happiness" is "the state of complete satisfaction" (de pleine satisfaction), "luck" and "success" (bonne, fortune, chance, prospérité, veine (familier)) [8], "good prediction" and "chance" [9]. "French happiness" is something that "falls on a person".

Similarly to Russian the French view of "happiness" can be marked as slightly sceptical due to its natural fluctuance; "happiness" is often seen as connected to "unhappiness", fleeting and easily replaced with sadness. In French phraseology "Happiness" is unrelated 
to outer, material goods and comforts, even perceived as incongruous with, for example, "money". Obtaining "creature comforts", if seen as the main life goal, makes it impossible for an individual to achieve "true", "elevated" happiness [10].

The idea of "elevation" can be traced philosophically, where parallels were established between "happiness" and "freedom (of flight), state of floating". Typical in this regard are the French phrases être aux anges (be with angels), être sur un nuage (be on a cloud), être au septième ciel (be on the sevenths sky) [11].

The survey among the French respondents revealed the following associations: love, pleasure, family, friends, travel, money, life/existence, laughter. In non-nominal associations such variants as "I am alive", "healthy", "I am not ill", "nobody in the family has Corona-virus", probably stimulated by the current pandemic, appeared. The ranking 10point scale analysis revealed that the French in the present world require "peace in their soul" (66\%), "harmony with self and world" (66\%), "freedom" (53\%), "health" (40\%).

\section{English perception}

For English-speaking people categorizing "happiness" appears to be a popular trend and an essential social research objective, as substantiated by numerous "Happiness Mind Maps" permeating personal blogs and articles on the beneficiality of investigating "happiness" and concepts (physiological, behavioural, metaphorical etc.), associated with it [12], [13].

Based on the data from the Representative Corpus of Historical English Registers (ARCHER, 1650-1990) H. Tissari, co-organizer of the Symposium on Happiness, identified the following causes of 'happiness': family, god, love, professional success, social relationships - which could be correlated with the concepts of affection, beauty, honour, illness/health, leisure, security, warmth [14], [15]. The comparative dictionary and phraseology data research by undergraduate students of the LUNN revealed these cognitive components of "happiness": appropriateness, delight, enthusiasm/readiness, euphoria, harmony, light-heartedness/irresponsibility, luck, peace/comfort, satisfaction/content. Almost none of the established constituents turned out to be linked to "material" world, especially intriguing for the American linguoculture stereotypically associated with "creature comforts". The English Google-form was thus specifically addressed to the American respondents, the free associative part successfully proving the abstract nature of "happiness", the most "material" answers being: mountain, smile, sun (none of which are "portable" objects).

The ranking part of the survey ( 1 to 10 scale) revealed that currently (the instability of life probably being the factor) "Peace" and "Harmony" are seen as the key to "happiness" (63,6\% of $10 / 10$ choices), with "Health" unsurprisingly coming second $(36,4 \%$ with varying $9 / 10,10 / 10$ rankings) and "Ability to do smth" - third (18,2\% with ranking varying from 7 to 10). With the majority of the respondents being 35 and younger a prediction is also possible to make about the possibility of "Affection" and "Acceptance" (with the most variable importance rankings) becoming more significant in the future.

\section{Conclusion}

"Happiness" is universally looked upon as one of the crucial constituents of human psycho-axiological paradigm and can be traced to cross-cultural universals.

The associative mapping of the concept "happiness" as perceived by the studied linguosocieties, shows both dichotomous and common trends in terms of providing a hierarchy of its fundamental traits. "Health", "family", "peace" and "freedom" are recognized as omnipresent elements. It is obvious that, notwithstanding their general 
importance, creature comforts are not thought to be overall happiness-productive. At the same time, the notion of "happiness" embodies a certain ethnic-specific realm. "Soul" comes to the limelight for Russians, the French attach significance to 'being alive' and not Corona-positive, while the English go for being active and capable of doing something.

The concept "happiness" is thus seen as a highly subjective phenomenon, integrating a wide variety of universal and personalized associations that are not necessarily directly connected with the mother-concept and require further investigation under the influence of present-day global transformations, providing ground for future research.

\section{References}

1. D. Myers, E. Diener, Perspectives on Psychological Science, 13(2), 218-225 (2018). https://doi.org/10.1177/1745691618765171.

2. A. Wierzbicka, Daedalus, 133(2), 32-43 (2004). https://doi.org/10.1162/001152604323049370.

3. P.A. Kragel, A.R. Knodt, A.R. Hariri, K.S. LaBar, PLoS Biol, 14(9), 1-4 (2016). https://doi.org/10.1371/journal.pbio.2000106.

4. Z. Derbisheva, Cuadernos de Rusística Española, 16, 55-68 (2020)

5. Academician: dictionaries and encyclopedias. Happiness (n.d.). Accessed on: December 24, 2020. [Online]. Available: https://dic.academic.ru/dic.nsf/vasmer/48444

6. A. Margulis, A. Kholodnaya, Russian-English Dictionary of Proverbs and Sayings. Bilingual edition (McFarland \& Company, North Carolina, 2008)

7. VTsIOM : the Economy and Pandemic Do Not Influence Russians' Happines. Fontanka (2020). Accessed on: November 13, 2020. [Online]. Available: https://www.fontanka.ru/2020/04/23/69109435/

8. C. Duneton, Le Bouquet des Expressions Imagées (Seuil, Paris, 2019)

9. F.G. Nazarjan, Slovar ustoichivih sravnenij francuzskogo jazika (RUDN, Moscow, 2018)

10. L.V. Krivoshlikova, Z.V. Kurguzenkova, Vestnik Rossijskogo universiteta druzhby narodov. Seria "Teorija jazika. Semiotika. Sematika", 1, 67-73 (2014)

11. A. Rey, Dictionnaire des expressions et locutions (Pobert, Paris, 2015)

12. S.G. Vorkachev, E.A. Vorkacheva, Concept of Happiness in the English Language: a Meaning Component, in Mass culture at the turn of the XX-XI centuries: a person and his discourse, 263-275 (Azbukovnik, Moscow, 2003)

13. M. Olkhovych-Novosadyuk, Linguistic Studies, 34, 118-123 (2017)

14. H. Tissari, Happiness and Joy in Corpus Contexts: A Cognitive Semantic Analysis, in Tissari H., Pessi A.B., Salmela M. (Eds.) Happiness: Cognition, Experience, Language, 144-174 (Helsinki Collegium for Advanced Studies, University of Helsinki, Helsinki, 2008)

15. D. Myers, E. Diener, Psychological Science, 6(1), 10-19 (1995). https://doi.org/10.1111/j.1467-9280.1995.tb00298.x. 